\title{
GH deficiency in adults
}

\author{
Dimitrios S Papadogias ${ }^{1}$, Polyzois Makras ${ }^{1}$, Gregory A Kaltsas ${ }^{1,2}$, John P Monson ${ }^{2}$ \\ Departments of Endocrinology, ${ }^{1}$ G. Gennimatas General Hospital, Athens Greece, ${ }^{2}$ St Bartholomew's Hospital, \\ London EC1A 7BE, UK
}

\begin{abstract}
Until the last decade, the diagnosis of GH deficiency (GHD) in adults was only considered as a marker of hypothalamo-pituitary disease. GHD in adults is now recognized as a specific clinical syndrome associated with a cluster of cardiovascular risk factors such as altered body composition with increased body fat, insulin resistance, adverse lipid profile, reduced physical performance, reduced bone mineral density and impaired quality of life. Several randomized placebo controlled trials have now established that GH replacement can reverse some of these biological changes and improve the overall health status in GHD adults; as a consequence, GH replacement therapy has now been approved in many countries in such patients. With the advent of recombinant technology, there is a virtually unlimited, safe supply of recombinant human GH. Although GH replacement is not administered as commonly as steroid, thyroid and sex hormones in hypopituitary patients, a six-month trial of GH replacement with re-evaluation of well-being, body composition and lipid profile is currently recommended. However, there is marked individual variability in the response to GH replacement, with IGF-I being the most sensitive serum marker of GH action. Questions yet remaining to be answered relate to the role of GH replacement in cases of partial GHD and its use in the elderly population. The safety of long term replacement therapy remains an important issue, particularly in relation to the cardio-vascular system, the incidence of de novo malignant tumours and the recurrence rate of pituitary tumours. In the context of safety, it remains essential to monitor patients by means of longitudinal surveillance databases.
\end{abstract}

Key words: growth hormone (GH), bone mineral density (BMD), lipoproteins, carbohydrate metabolism, quality of life

\section{INTRODUCTION}

GH deficiency in adults, commonly resulting from pituitary or peri-pituitary tumours and/or their treatment, is characterized by a diversity of symptoms and

\footnotetext{
Address correspondence and requests for reprints to: Dr GA Kaltsas, Department of Endocrinology, Diabetes, Metabolism, G. Gennimatas General Hospital, Athens, Greece, Tel: 003210 7778901, Fax: 0030210 7779146, E-mail:gkaltsas@acci.gr

Received 21-07-03, Revised 17-08-03, Accepted 20-09-03
}

signs $^{1}$. Adults with GH deficiency are less healthy than their age-matched peers, and GHD has been implicated in increased mortality, mainly from cardiovascular disease (CVD) observed in patients with hypopituitarism who receive replacement hormones other than $\mathrm{GH}^{2,3}$. A number of clinical trials have now documented that GH replacement results in sustained benefits in adult patients with $\mathrm{GHD}^{4-7}$. However, GH replacement treatment is not offered to all adult GHD patients; its routine use is still a matter of debate, mainly due to the lack of prospective studies using as 
an end point an overall reduction of cardiovascular mortality. This review will focus on the clinical manifestations and diagnostic confirmation of adult GHD as well as the response to GH replacement treatment. Since the prevalence of adult onset GHD is estimated at approximately $1-3$ in 10,000 of the population ${ }^{8}$, it is important to identify the group of patients who will most benefit from this treatment.

\section{CLINICAL AND METABOLIC MANIFESTATIONS}

Adults with GHD have altered body composition, with an increase in total body fat as well as an abnormal distribution of fat, mainly abdominal accumulation of excessive adipose tissue, decreased lean body mass, increased LDL-cholesterol, slightly reduced HDL-cholesterol levels and insulin resistance ${ }^{1}$. Total body water and circulating extracellular volume are reduced and this together with an increase in subcutaneous fat results in poor venous access ${ }^{9}$. Adult GHD is also associated with decreased muscle strength and reduced physical and cardiac performance ${ }^{1,8}$. In addi- tion, patients with adult GHD also have reduced bone mineral density (BMD) and increased incidence of fractures $^{10,11}$ (Table 1). Comparison of data from KIMS (International Pharmaco-epidemiological Survey of the use of GH replacement therapy in adults sponsored by Pfizer Corporation) with data from a control non-GH deficient population showed that prevalence of fractures was 2.66 times higher in KIMS patients over 60 years with hypopituitarism ${ }^{12}$. Finally, one of the most striking features of this syndrome is a reduced sense of physical and psychological well-being 8 . Using validated questionnaires based on symptoms most frequently identified by GHD adults, patients report less energy, emotional lability, lower openness, difficulties with memory and attention, low self-confidence and self-esteem, a sense of social isolation and diminished libido ${ }^{1}$.

\section{DIAGNOSIS OF GH DEFICIENCY}

Patients at risk (patients who should be screened)

All patients with evidence of hypothalamic-pitu-

Table 1. Bone mineral density, body composition and lipid profile in adults with growth hormone deficiency

\begin{tabular}{|c|c|c|c|c|c|c|c|}
\hline Study & $\begin{array}{c}\text { No of } \\
\text { patients }\end{array}$ & $\begin{array}{c}\text { Body } \\
\text { composition }\end{array}$ & $\begin{array}{c}\text { Bone mineral } \\
\text { density }\end{array}$ & $\begin{array}{c}\text { Total } \\
\text { Cholesterol }\end{array}$ & TG & LDL-C & HDL-C \\
\hline Bing-You et al ${ }^{78}$ & 14 & NA & Total body $8 \%$ decrease & NA & NA & NA & NA \\
\hline Holmes et $\mathrm{al}^{79}$ & 26 & NA & $\begin{array}{l}\text { Changes in } \\
\text { z score: lumbar } \\
\text { spine, }-0.76 ; \\
\text { femoral neck }-0,38\end{array}$ & NA & NA & NA & NA \\
\hline Attanasio et $\mathrm{al}^{72}$ & 106 & $\begin{array}{l}\text { 2.4-kg ncrease } \\
\text { in fat mass in men, } \\
\text { 3.3-kg increase in fat } \\
\text { mass in women }\end{array}$ & NA & NA & NA & NA & NA \\
\hline Rutherford et $\mathrm{al}^{81}$ & 11 & $\begin{array}{l}18-22 \% \text { increase } \\
\text { in fat mass } 1 \mathrm{yr} \\
\text { after discontinuation } \\
\text { of GH therapy }\end{array}$ & NA & NA & NA & NA & NA \\
\hline Markussis et $\mathrm{al}^{41}$ & 34 & NA & NA & $19 \%$ increase & NA & $\begin{array}{c}23 \% \\
\text { increase }\end{array}$ & No change \\
\hline Kaufman et $\mathrm{al}^{11}$ & 30 & NA & $\begin{array}{c}\text { Total BMD } \\
\text { decreased }\end{array}$ & NA & NA & NA & NA \\
\hline De Boer et $\mathrm{al}^{25}$ & 64 & NA & NA & Increased & No change & Increased & No change \\
\hline Drake WM et $\mathrm{al}^{24}$ & 13 & NA & $\begin{array}{l}\text { Increased in men } \\
\text { preserved in women } \\
\text { after 5yr of GH } \\
\text { replacement }\end{array}$ & NA & NA & NA & NA \\
\hline
\end{tabular}

NA denotes not assessed. 
itary disease, history of cranial irradiation or childhood onset GHD should undergo evaluation for the presence of adult GH deficiency. The diagnosis is best established with the use of a provocative test of GH secretion ${ }^{13}$. The insulin tolerance test (ITT) is considered to be the test of choice. Using this test, severe GHD is defined as a peak GH response below $3 \mu \mathrm{g} /$ $\mathrm{L}^{13}$. In cases where the ITT is contraindicated (patients with coronary heart disease, generalized debility and/ or epilepsy), the combined administration of arginine and growth hormone releasing hormone (GHRH) is an acceptable alternative ${ }^{13}$. Another promising diagnostic tool that has to be further validated is the combined administration of GHRH plus Growth Hormone Releasing Hexapeptide (GHRP -6) ${ }^{14}$. Tests using arginine alone or glucagon alone are considered less stringent with less diagnostic value. In order to avoid false positive results, particularly in cases of obesity, the diagnosis of isolated adult GHD should be based upon abnormal findings on two dynamic tests $^{13}$. Adult patients with hypothalamic-pituitary disease and one or more additional pituitary hormone deficits require only one provocative test to confirm the diagnosis ${ }^{8,13}$.

GH dependent peptides, such as IGF-I, are used as markers of GH adequacy, although normal IGF-I levels cannot exclude the diagnosis of adult $\mathrm{GHD}^{8,13}$. Conversely, in the presence of structural pituitary disease and/or multiple pituitary hormone deficits, a very low serum IGF-I indicates a high probability of GH deficiency ${ }^{13}$. It should also be noted that serum IGF-I concentration may also be reduced by poor nutrition, hepatic disease, poorly controlled diabetes mellitus and inadequately treated hypothyroidism. Measurement of serum IGF-Binding Protein-3 (IGFBP-3) or acid labile subunit has to date not proven to offer any advantage over the measurement of serum IGF- ${ }^{13}$.

\section{RESPONSE TO TREATMENT}

\section{Body composition}

Several studies, using different techniques, have demonstrated that GHD in adult males is associated with a $7 \%$ mean increase in total body fat, which is mainly distributed centrally (around the abdomen), and a mean reduction in lean body mass (LBM) of 7$8 \%$. In addition, bioimpendance analysis has shown that the hydration state of LBM is lower than normal due to a decrease in extracellular water ${ }^{15}$. In these patients, body muscle mass and plasma IGF-I levels are positively correlated. These changes appear to be reversible following the initiation of GH treatment. Studies have consistently shown a mean increase in LBM averaging between $2-5.5 \mathrm{~kg}$ within several months of GH therapy, and this is associated with a similar reduction in fat mass ${ }^{1}$. Although the effect on LBM is maintained even for a $10 \mathrm{yr}$ period, the reduction in fat mass is not sustained ${ }^{4}$; these changes in body composition appear to be more pronounced in men than in women but this may simply reflect differences in GH sensitivity and IGF-I generation and are not evident when the GH dose is titrated against IGF$\mathrm{I}^{16,17}$. Interestingly, a recent study examining the changes of fat distribution in male and female GHD adults during the first year of discontinuation of GH therapy showed that the subcutaneous and intrabdominal fat mass increased dramatically in young GHD adults, especially within the first three months ${ }^{18}$.

Lean body mass has also been found to be the single predictor of basal metabolic rate (BMR) and resting energy expenditure (REE). In GHD adults, REE is lower than predicted after correction for age, height and weight ${ }^{1}$. GH replacement rapidly increases REE, an effect that can be attributed not only to the increase in LBM, and therefore to increased protein synthesis, but also to increased cellular metabolism, increased fat oxidation and increased peripheral conversion of thyroxine (T4) to tri-iodothyronine (T3) which is mediated by $\mathrm{GH}^{19}$.

\section{Bone Mineral Density (BMD)}

Patients with adult onset GHD have lower BMD compared to normal subjects and the degree of osteopenia is directly correlated with circulating IGF-I levels ${ }^{20}$. Increased bone loss and decreased bone remodelling may be involved in the pathogenesis of reduced bone mass in patients with adult onset pituitary deficiency. Biochemical markers of bone turnover in adult GHD are associated with a decreased remodelling rate. Several studies have shown no difference in BMD between patients with isolated GHD and those with multiple pituitary hormone deficiency of childhood onset, suggesting that GHD may be a key factor for reduced bone mass in these patients, probably as a consequence of failure to achieve peak bone mass ${ }^{11}$. Low BMD is associated with a doubling of the fracture rate compared to healthy controls ${ }^{21}$. 
GH is regarded as an osteo-anabolic hormone and when given to GHD adults exerts a biphasic effect: following an initial net increase of bone resorption, stimulation of bone formation leads to a net gain in bone mass after 12-24 months of treatment ${ }^{1}$. In a placebo controlled study, GH treatment in GHD adults was associated with a 5\% increase of BMD in the spine and $2 \%$ in the femoral neck ${ }^{5}$. In this study, BMD increased at sites composed mostly (lumbar spine) or partially (femoral neck) of trabecular bone but not at

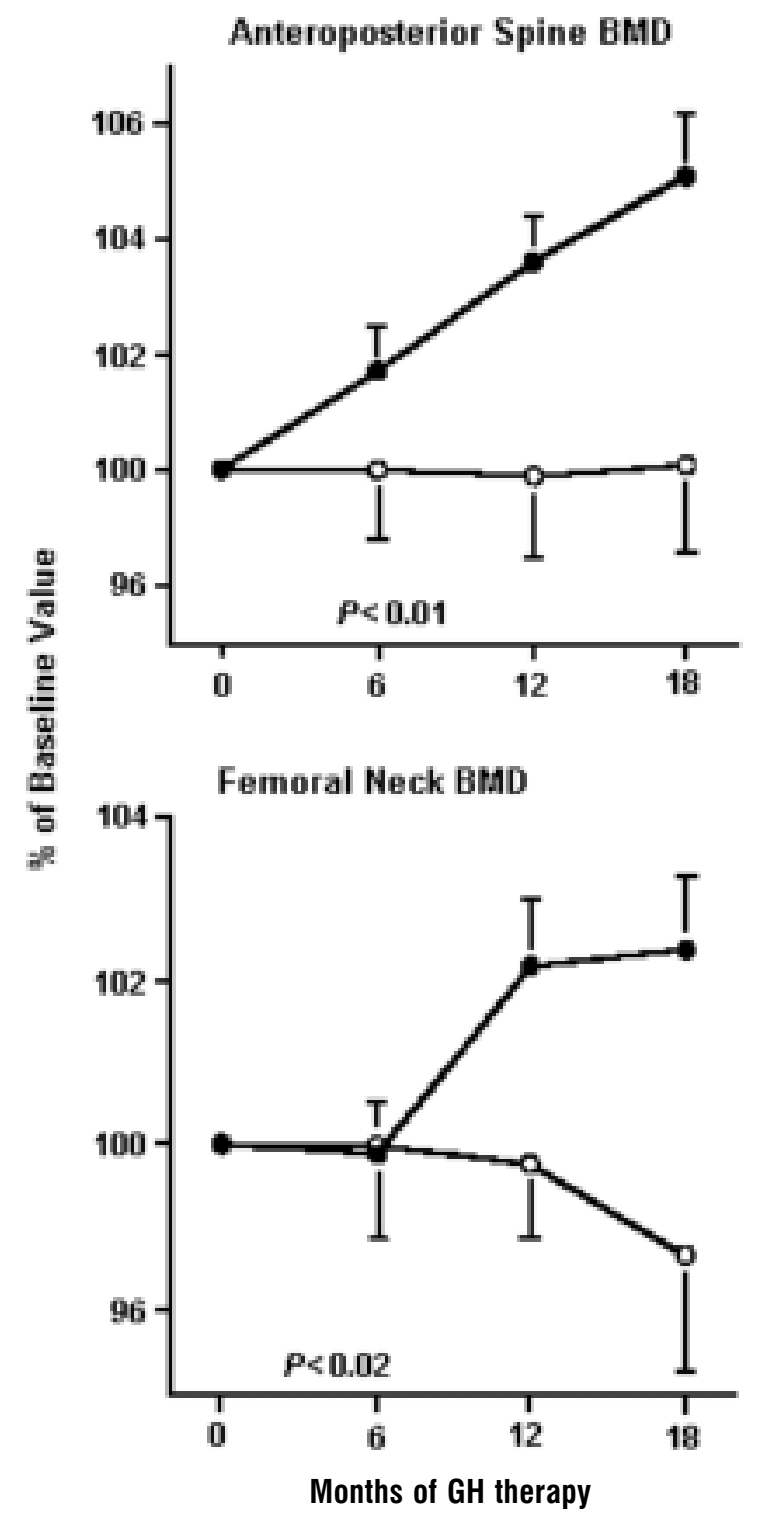

a site composed of cortical bone (proximal radius), suggesting that beneficial effects of GH therapy occur primarily in trabecular bone (Figure 1). The improvement in BMD persisted for 18 months after discontinuation of the treatment ${ }^{22}$. Furthermore, analysis of data from patients enrolled in KIMS has provided the first evidence from a large-scale survey that patients with hypopituitarism and GHD have a higher prevalence of fractures than the general population and that GH substitution therapy reduces frac-

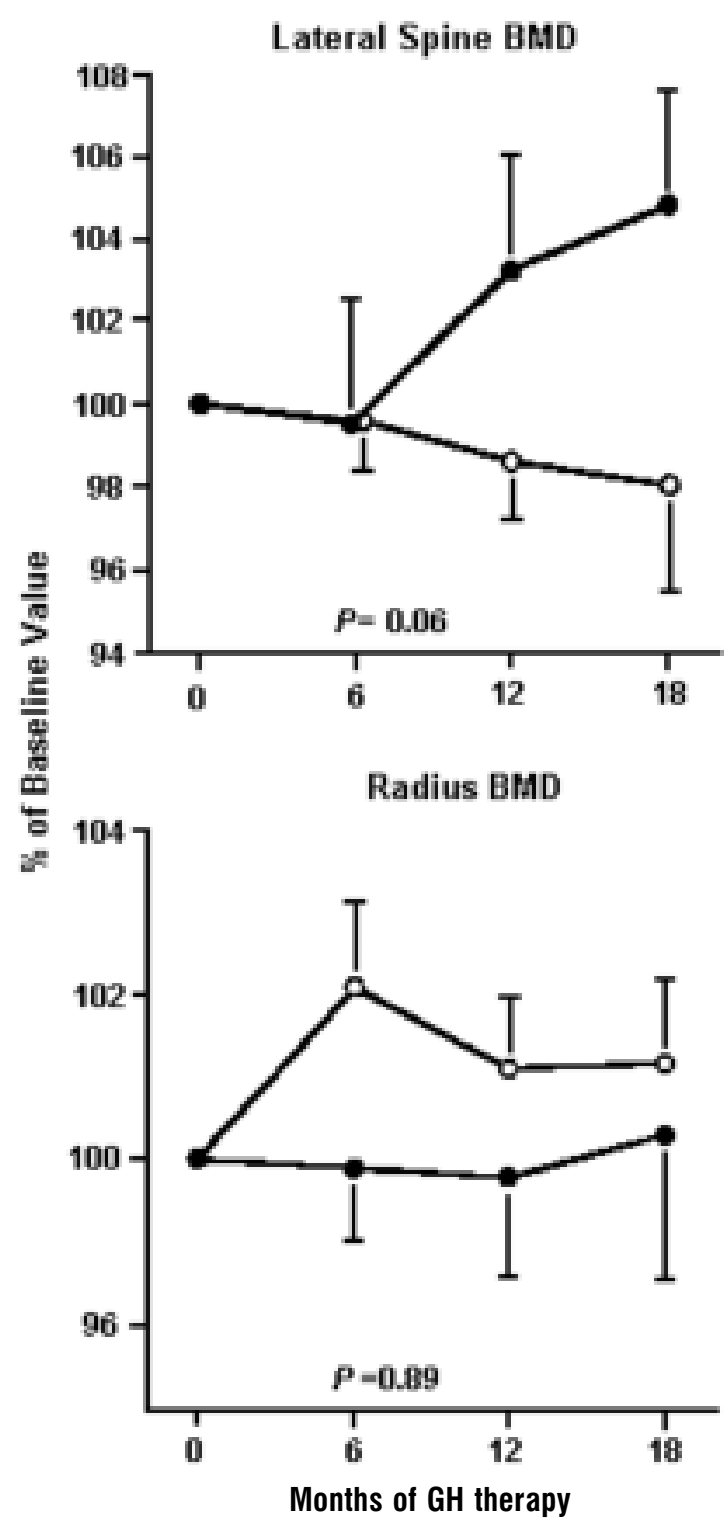

Figure 1. Bone mineral density (BMD) of the lumbar spine in the anteroposterior projection, lateral projection, femoral neck and of the one third distal radius in patients with growth hormone deficiency receiving growth hormone $(\bullet)$ or placebo $(O)$. Values are percentages of the baseline values, and error bars represent \pm 1 SE. P values are for comparisons of rates of change between the two groups.(Reproduced with permission from Annals of Internal Medicine, 1 December 1996, 125:883-890). 
ture risk ${ }^{12,23}$. Longitudinal data from a 5-year study confirmed that long-term GH treatment in hypopituitary adults with GH deficiency results in an increase in BMD in males and stabilization of BMD in females both at lumbar spine and femoral neck ${ }^{24}$.

\section{Muscle strength}

Decreased LBM in GHD adults results in mild to moderate reduction in muscle strength. Skeletal muscle force may be reduced due to altered muscle mass, contractile elements and/or muscle fibre, anaerobic energy supply, neural recruitment of fibres, or a combination of these $\mathrm{e}^{25}$. The administration of growth hormone to GHD adults increases LBM, muscle volume and maximum voluntary isometric muscle strength but not local muscle endurance or dynamic muscle strength ${ }^{6,26}$.

\section{Lipid profile}

$\mathrm{GH}$ affects lipoprotein metabolism by increasing both lipoprotein production and secretion from the liver and their clearance from the circulation by upregulating expression of hepatic LDL receptor ${ }^{27}$. $\mathrm{Pa}$ tients with GHD have mild hypercholesterolemia due to increased LDL-cholesterol and apolipoproteins B levels while LDL-cholesterol levels are inversely related to GH secretory status ${ }^{28}$. Compared with age, weight and sex-matched controls, adult GHD patients have higher serum triglyceride and lower high-density lipoprotein (HDL) cholesterol levels ${ }^{29}$. GH treatment results in a less atherogenic profile, with a significant reduction in LDL cholesterol levels, which has been maintained over a 10 -year period ${ }^{4}$. The adverse lipid profile in GHD adults and its attenuation with $\mathrm{GH}$ replacement is more pronounced in women ${ }^{8}$. Observational data from patients who had completed 3 years of GH treatment showed an overall increase of HDL-cholesterol and a significant decrease in the $\mathrm{LDL} / \mathrm{HDL}$ ratio, which is considered a strong discriminator for the risk of coronary heart disease ${ }^{30}$. Of note, these changes were greater in the older and middle age groups of patients but not in patients younger than 40 years $^{30}$. In addition, GH therapy increase Lipoprotein a $(\operatorname{Lp}(\mathrm{a}))$ levels and this effect is not influenced by the apolipoprotein (a) phenotype ${ }^{31,32}$. Effects of GH replacement therapy on body composition and lipid profile in adults with GHD are outlined in Table 2.

\section{Carbohydrate metabolism and insulin sensitivity}

Adults with GHD are insulin resistant due to an increase in total and visceral fat and the development of central obesity ${ }^{33}$. The degree of insulin resistance depends on the extent of the obesity and probably the duration of $\mathrm{GH}$ deficiency ${ }^{1}$. GH replacement therapy during the first year of therapy results in relative hyperinsulinemia with further deterioration in insulin sensitivity and increases of glucose concentrations. Subsequently, glucose concentrations return towards baseline, probably due to the beneficial changes of GH replacement in body composition ${ }^{1,8}$. In a placebo controlled study, insulin sensitivity remained unchanged after 7 years of $\mathrm{GH}$ replacement and showed a tendency to remain higher at the end of the study than at baseline in the treated compared to the un-

Table 2. Effects of growth hormone replacement therapy on body composition and lipid profile in adults with growth hormone deficiency

\begin{tabular}{|c|c|c|c|c|c|c|c|c|c|}
\hline Study & $\begin{array}{c}\text { Number } \\
\text { of patients }\end{array}$ & $\begin{array}{c}\text { Duration } \\
\text { of Therapy }\end{array}$ & $\begin{array}{l}\text { Lean Body } \\
\text { Mass }\end{array}$ & Adipose mass & $\begin{array}{c}\text { Total } \\
\text { Clolesterol }\end{array}$ & LDL-C & HDL-C & TG & $\operatorname{Lp}(\mathbf{a})$ \\
\hline Whitehead $^{6}$ & 14 & $6 \mathrm{mo}$ & $7 \% \uparrow$ & $10 \% \downarrow$ & no change & no change & no change & no change & NA \\
\hline Cuneo $^{26}$ & 24 & $6 \mathrm{mo}$ & - & - & $12 \% \downarrow$ & $24 \% \downarrow$ & no change & $24 \% \downarrow$ & NA \\
\hline Attanasio $^{80}$ & $\begin{array}{l}\text { AO } 52 \\
\text { CO } 32\end{array}$ & $6 \mathrm{mo}$ & $\begin{array}{l}\mathrm{AO}: 3.5 \mathrm{~kg} \uparrow \\
\mathrm{CO}: 3, .7 \mathrm{~kg} \uparrow\end{array}$ & $\begin{array}{l}\text { AO: } 4.9 \% \downarrow \\
\text { CO:5.5\% }\end{array}$ & $\begin{array}{l}\mathrm{AO}: 8 \% \downarrow \\
\mathrm{CO}: 5 \% \downarrow\end{array}$ & $\begin{array}{c}\mathrm{AO}: 11 \% \downarrow \\
\mathrm{CO}: 5 \% \downarrow\end{array}$ & $\begin{array}{l}\mathrm{AO}: 23 \% \uparrow \\
\mathrm{CO}: 12 \% \uparrow\end{array}$ & NA & NA \\
\hline Bengtsson $^{7}$ & 9 & $6.5 \mathrm{mo}$ & $3.9 \mathrm{~kg} \uparrow$ & $6 \mathrm{~kg} \downarrow$ & no change & NA & NA & no change & NA \\
\hline Salomon $^{53}$ & 11 & $6 \mathrm{mo}$ & $5.5 \mathrm{~kg} \uparrow$ & $5.7 \mathrm{~kg} \downarrow$ & $12 \% \downarrow$ & NA & NA & no change & NA \\
\hline Baum $^{5}$ & 16 & $1.5 \mathrm{yr}$ & $4 \% \uparrow$ & $11 \% \downarrow$ & NA & NA & NA & NA & NA \\
\hline $\operatorname{Eden}^{28}$ & 9 & $\begin{array}{l}6 \mathrm{wk} \\
26 \mathrm{wk}\end{array}$ & NA & NA & $\begin{array}{c}\downarrow \\
\text { no change }\end{array}$ & $\begin{array}{c}\downarrow \\
\text { no change }\end{array}$ & $\begin{array}{l}\uparrow \\
\uparrow\end{array}$ & $\begin{array}{l}\text { no change } \\
\text { no change }\end{array}$ & $\begin{array}{l}\uparrow \\
\uparrow\end{array}$ \\
\hline Rosen $^{82}$ & 25 & $1 \mathrm{yr}$ & $4 \% \uparrow$ & $8 \% \downarrow$ & no change & NA & $12 \% \uparrow$ & no change & NA \\
\hline Weaver $^{83}$ & 22 & $1 \mathrm{yr}$ & NA & $1.8 \mathrm{~kg} \downarrow$ & $\downarrow$ & NA & NA & no change & $\uparrow$ \\
\hline
\end{tabular}

NA denotes not assessed, AO: Adult onset, $\mathrm{CO}$ : Childhood onset. 
treated patients ${ }^{34}$. The overall risk of developing diabetes mellitus is not increased during $\mathrm{GH}$ replacement therapy, although GHD patients with low baseline insulin sensitivity are at increased risk ${ }^{8,34}$. In a two year study, GH replacement therapy given at a low titrated dose resulted in modest increment in mean fasting glucose and mean glycated haemoglobin, both of which remained within the reference range ${ }^{35}$. In this study a weak but significant correlation was found between the increment in $\mathrm{HbA} 1 \mathrm{c}$ and pretreatment BMI.

\section{Cardiovascular function}

Patients with hypopituitarism receiving conventional hormonal replacement therapy excluding $\mathrm{GH}$ have a mortality rate twice that of age and sex-matched normal subjects, a difference attributable to an increased number of cardiovascular events and implicating GHD as an etiological factor ${ }^{3}$. Loss of GH secretion is an early event in the development of pituitary deficiency and it can therefore be assumed that the majority of patients with hypopituitarism are also $\mathrm{GH}$ deficient. Both GH and IGF-I receptors are expressed in the heart and these hormones may be involved in the developmental growth and maintenance of the structure of the heart ${ }^{36,37}$. Their effects can be either direct, acting on the endothelial cells, or indirect modifying established risk factors linked to atherosclerosis ${ }^{38,39}$ GHD in adults is associated with a disturbed lipoprotein pattern, higher incidence of hypertension, abnormal body composition, impaired glucose homeostasis, hypercoaguability, increased intima-medial thickening and arterial intimal plaque formation, premature atherosclerosis, impaired cardiac function and a decrease in exercise capacity ${ }^{39-41}$. $\mathrm{Pa}$ tients with GHD also have increased sympathetic nerve activity, probably of central origin, leading to hypertension, contributing further to the increased cardiovascular mortality ${ }^{42}$. Nitric oxide generation has been found to be low and endothelium dependent vasodilatation is impaired in GHD adults and improves with $\mathrm{GH}$ replacement therapy ${ }^{43,44}$. These changes result in an increased atherogenic propensity and may contribute to premature cardiovascular mortality ${ }^{1}$. Interestingly, in one study treatment with GH normalized the intima-media thickness of the common carotid artery within 6 months and that of the carotid bifurcation within 3 months ${ }^{45}$. Factors that accelerate atherosclerosis in GHD adults are outlined in Table 3.

Adult GHD, particularly of childhood onset, leads
Table 3. Risk Factors For Atherosclerosis Associated With Adult Growth Hormone Syndrome

Increased visceral fat

Increased insulin resistance

Increased LDL-cholesterol and ApoB

Decreased HDL-cholesterol

Higher incidence of hypertension

Increased carotid intima-medial thickness

Decreased nitric oxide generation - Impaired endothelium dependent vasodilation

Hypercoaguability ( $\uparrow$ plasminogen activator inhibitor, $\uparrow$ fibrinogen)

Increased inflammatory markers of vascular disease ( $\uparrow \mathrm{CRP}$ )

to a reduction in the mass of both ventricles and impaired cardiac performance with low heart rate (hypokinetic syndrome $)^{46}$. These alterations are particularly evident during physical exercise and may contribute to the reduced exercise capacity of GHD patients, in addition to the reduced muscle mass and strength $^{47}$. A short term placebo controlled study demonstrated that GHD adults had significant cardiac impairment (reduced left ventricular mass index, reduced left ventricular systolic function associated with decreased fractional shortening and rate-adjusted mean velocity of circumferential fibre shortening $)^{48}$. Treatment with recombinant GH for 6 months resulted in normalization of echocardiographic findings, while six months after cessation of therapy, cardiac function had returned to pretreatment levels ${ }^{48}$. In another study of thirty adults with acquired GHD, cardiac output increased by 30 to $40 \%$ and total peripheral resistance decreased by approximately $30 \%$ during GH therapy ${ }^{43}$. Six months of GH replacement have been shown to increase left ventricular mass, stroke volume and cardiac output, and reduce peripheral vascular resistance in GHD adults ${ }^{49}$. A sustained effect on cardiac performance has been reported to be maintained up to 3 years after commencement of GH therapy ${ }^{1}$. It is important, however, to monitor the longterm cardiovascular effects of GH replacement as the correct physiological GH replacement regimen is not known, whereas persistently elevated IGF-I levels are related to excess cardiovascular mortality in acromegalic patients ${ }^{46}$.

\section{Quality of life (QoL) and well-being}

GHD in adults causes distress and poor well-being $^{50}$. Patients with adult GHD feel less energetic and 
less healthy than normal subjects of the same age (alterations of sleeping pattern, greater emotional lability, more difficulties with sexual relationships, greater sense of social isolation, poor concentration and memory difficulties $)^{26,50}$. Although methods evaluating and monitoring physical and emotional well-being carry inherent limitations, recent developments have provided more sensitive scoring systems, such as the adult GHD assessment (QoL-AGHDA) score ${ }^{51}$. This is a questionnaire comprising 25 items based on the symptoms most frequently reported by GHD adults. Questions regarding energy, physical and mental drive, concentration, memory, personal relationships, social life, cognition and emotions are included and a single score is obtained (Table 4). Initial placebo controlled trials (which did not use the QoL-AGHDA score) have documented statistically significant

Table 4. Quality of life assessment of GH deficiency in adults (AGHDA score)

1. I have to struggle to finish jobs.

2. I feel a strong need to sleep during the day

3. I often feel lonely even when I am with other people

4. I have to read things several times before they sink in

5. It is difficult for me to make friends

6. It takes a lot of effort for me to do simple tasks

7. I have difficulty controlling my emotions

8. I often lose track of what I want to say

9. I lack confidence

10. I have to push myself to do things

11. I often feel very tense

12. I feel as if I let people down

13. I find it hard to mix with people

14. I feel worn out even when I've not done anything

15. There are times when I feel very low

16. I avoid responsibilities if possible

17. I avoid mixing with people I don't know well

18. I feel as if I am a burden to people

19. I often forget what people have said to me

20. I find it difficult to plan ahead

21. I am easily irritated by other people

22. I often feel too tired to do things I ought to do

23. I have to force myself to do all the things that need doing

24. I often have to force myself to stay awake

25. My memory lets me down. improvements in quality of life after the initiation of GH replacement therapy ${ }^{1,7,52}$. This effect of GH replacement therapy is seen within 3 to 6 months of treatment and is sustained throughout the duration of GH replacement ${ }^{1,8}$. The speed of onset of improvement before any expected increase in muscle strength and cardiac performance and the fact that this occurs despite only small increments in serum IGF-I levels suggests a direct $\mathrm{GH}$ effect on the brain ${ }^{1,51}$. In addition, GH replacement therapy resulted in a significant decrease in the number of days of 'sick leave', the number of days in hospital and the number of visits to the doctor $^{53}$. In current clinical practice, a 6-month course of GH replacement should be undertaken to assess clearly QoL benefits in GHD adults ${ }^{8}$.

\section{Who's to be treated}

All patients with documented severe GHD are eligible for GH replacement, the goal being to correct abnormalities associated with GHD ${ }^{13}$. Lack of wellbeing and abnormal body composition remain the most common reasons to consider a trial of GH replacement therapy in adults, and they represent the most useful clinical markers of GH efficacy during replacement ${ }^{54}$. Recently, $\mathrm{GH}$ has also been approved by the FDA for use in human immunodeficiency virus (HIV) associated wasting states in adults ${ }^{55}$. Absolute contraindications for $\mathrm{GH}$ replacement therapy are active malignancy, benign intracranial hypertension and proliferative or pre-proliferative diabetic retinopathy ${ }^{13}$. Well controlled diabetes mellitus is not a contraindication; however, as GH antagonizes insulin effects, careful monitoring is required ${ }^{56}$. Stable background retinopathy should not lead to discontinuation of GH replacement ${ }^{56}$. Early pregnancy is not a contraindication, but GH should be discontinued in the second trimester as $\mathrm{GH}$ is produced by the placenta $^{13}$.

\section{Optimal GH dose}

In the initial studies, a weight or surface area based dosing regimen was employed ${ }^{6,57,58}$. This was based on experience gained from treatment of GHD children and resulted in GH daily doses of approximately $25 \mu \mathrm{g} /$ $\mathrm{kg}$ that were associated with supranormal levels of serum IGF-I levels and high rates of side effects ${ }^{17}$. Adults with GHD are more susceptible than children to side effects, especially at the initiation of therapy ${ }^{55}$. Subsequent studies have shown that GH replacement 
should be commenced using a dose titration regimen based on measurements of serum IGF-I ${ }^{17}$. Recombinant human GH is administered as subcutaneous injection once a day, usually in the evening. Since it is not possible to recreate normal physiology with a single subcutaneous injection of GH, the goal of treating GHD adults is correction of the associated clinical syndrome. Therapy should start at a low dose of $0.15-0.30 \mathrm{mg} /$ day $(0.45-0.9 \mathrm{IU} /$ day $)$ with gradual increase thereafter ${ }^{13}$. Peak level is reached at approximately 4-6 hours after an injection, with a length of disappearance of 20-24 hours ${ }^{59}$. Based on clinical and biochemical responses, the dose is reviewed every 2-4 weeks. Women require a higher dose than men; elderly patients tolerate $\mathrm{GH}$ less than young adults, but are more sensitive to $\mathrm{GH}$ treatment ${ }^{13,55}$.

Measurement of IGF-I levels represents the best single test to monitor the adequacy of GH treatment ${ }^{60}$. The aim is to achieve a serum IGF-I level between the median and the upper end of the age-related reference range for the patient by using the minimum dose of $\mathrm{GH}^{8}$. Serum IGF-I levels increase and then plateau at 2 weeks after an alteration in $\mathrm{GH}$ dose and measurements at this time reliably reflect GH activity for titration purposes ${ }^{17}$. The dose should be increased gradually on the basis of clinical and biochemical responses and no more frequently than at monthly intervals ${ }^{13}$.

\section{Side effects and surveillance during therapy}

The most common side effects of GH treatment in adults with hypopituitarism are arthralgia, myalgia, carpal tunnel syndrome and paresthesias which are related to the antinatriuretic actions of $\mathrm{GH}^{51}$. These symptoms are more frequent with higher doses and subside following dose reduction ${ }^{1}$. Benign intracranial hypertension occurs more frequently in children and improves with the cessation of therapy ${ }^{19}$. Furthermore, $\mathrm{GH}$ induces transient resistance to the actions of insulin and in patients with limited insulin reserve glucose intolerance may result ${ }^{34,61}$. Side effects of GH replacement are more likely to occur in older patients, in those with a peak serum GH response to provocative testing of greater than $1 \mathrm{mU} / 1$, in those with a greater increment in serum IGF-I whilst receiving GH replacement, and in those with greater weight and $\mathrm{BMI}^{62}$.

Although the risk of certain malignancies (e.g. colon cancer) is increased in patients with acromegaly, it would have been inappropriate to extrapolate that GH replacement in adults will have similar consequences. Importantly, analysis of data from patients enrolled in KIMS indicate no increased risk of cancer recurrence or de novo malignancies after GH replacement, and mortality rates appear no different from age, sex and country adjusted mortality rates ${ }^{61}$. Based on the limited data available, there is no evidence that $\mathrm{GH}$ treatment increases either the risk of a second malignancy in subjects who have already had a malignancy or de novo cancer or leukemia ${ }^{56}$. Although patients with a pituitary tumour or craniopharyngioma are at risk of tumour recurrence, there is no evidence that $\mathrm{GH}$ replacement therapy increases this risk ${ }^{61}$. Although GH replacement titrated against serum IGFI is not associated with early increase in the recurrence rate or re-growth of hypothalamo-pituitary tumours, a baseline scan is recommended in all patients before instituting $\mathrm{GH}$ replacement therapy ${ }^{63}$.

Some concern has been raised recently by reports associating high-normal IGF-I levels with prostate cancer risk and breast cancer risk in premenopausal women $^{64,65}$. However, it is difficult to interpret these findings since neither prostate nor breast cancer appears with increased incidence among acromegalic patients ${ }^{66}$.

Monitoring of thyroid function should be conducted in all patients since $\mathrm{GH}$ increases extrathyroidal conversion of T4 to T3 and may unmask incipient hypothyroidism $^{56}$. Finally, by inhibiting $11 \beta$-hydroxysteroid deydrogenase type I activity, GH results in enhanced net conversion of cortisol to inactive cortisone; this might hypothetically precipitate adrenal insufficiency in patients with borderline ACTH deficiency or those receiving a relatively low dose of hydrocortisone replacement ${ }^{54,67}$. Moreover, relatively high dose GH may decrease serum total cortisol concentrations by decreasing circulating cortisol binding protein $(\mathrm{CBP})^{52,68}$.

\section{FUTURE PROSPECTS}

Growth hormone therapy is beneficial in adults and children primarily as a replacement therapy. The wideranging physiological effects of endogenous $\mathrm{GH}$ have led to the use of GH therapy in a range of other conditions ${ }^{69}$. So far the use of GH has also been studied in small numbers of adults with burn injuries, respira- 
tory failure, congestive cardio-myopathy and renal failure, after liver transplantation and during recovery from surgery. To date no consistent benefit has been demonstrated ${ }^{70}$. Furthermore, in a double blind, placebo controlled trial involving severely ill patients necessitating intensive care, administration of high doses of GH was associated with increased morbidity and mortality ( $42 \%$ mortality in the GH-treated group compared to $18 \%$ of placebo $)^{71}$. GH stimulates bone remodelling activity, opening up the possibility that $\mathrm{GH}$ can be added to antiresorptive agents in the treatment of osteoporosis. In a study designed to test this hypothesis, GH given cyclically with or without calcitonin for $2 \mathrm{yrs}$ increased BMD at the lumbar spine and selected areas of the hip in postmenopausal women, but improvements were less marked than those achieved with estrogen or bisphosphonates and were associated with a relatively high incidence of adverse experiences $^{72}$. GH therapy has been studied in men with features of the metabolic syndrome and is associated with an early improvement in insulin sensitivity and a beneficial effect on diastolic blood pressure and lipid profile ${ }^{69,73}$.

Of special interest is the use of GH during the transition period from adolescence to adulthood because this period involves the achievement not only of adult height but also of peak bone mass, adult body composition and reproductive maturity ${ }^{70}$. Peak bone mass is attained some years after final height while discontinuation of GH therapy in adolescents with severe GHD may lead to detrimental changes in body composition, lipid profiles and cardiac structure ${ }^{74,75}$. However, not all patients with childhood onset GHD will remain growth hormone deficient as adults, as a significant proportion of patients with idiopathic childhood onset GHD produce GH responses within the normal range when retested as adults ${ }^{76,77}$. Thus, a stimulation test in patients who have achieved their final height should be undertaken to identify the patients who may be at risk of developing the adult GHD syndrome. Patients with a $\mathrm{GH}$ response less than $5 \mu \mathrm{g} / \mathrm{L}$ on ITT are most likely to develop GHD in adulthood if $\mathrm{GH}$ treatment is stopped at final height ${ }^{77}$. Other uses of $\mathrm{GH}$ are under investigation and an area of special interest is the development of orally active $\mathrm{GH}$ secretagogues for those patients who might benefit from $\mathrm{GH}$ therapy and in whom hypothalamic-pituitary function is intact ${ }^{76}$.

\section{SUMMARY}

Growth hormone deficiency (GHD) in adults is now recognized as a specific clinical syndrome, commonly resulting from pituitary or hypothalamic disease associated with unfavourable effects on body composition, lipid metabolism, bone mass and quality of life. Untreated GHD has been regarded as a factor implicated in the increased cardiovascular mortality observed in patients with hypopituitarism. So far, an extensive array of clinical trials and longitudinal studies have documented that $\mathrm{GH}$ replacement therapy provides both physical and psychological benefits. Diagnosis of GHD in adults should be based on provocative testing of $\mathrm{GH}$ secretion and the dose of $\mathrm{GH}$ replacement therapy should be titrated against serum IGF-I in place of weight-based dosing regimens. The appearance of secondary malignancy does not appear to be increased, but longer surveillance studies are needed to monitor the safety of GH treatment.

\section{REFERENCES}

1. Caroll PV, Christ ER and the members of Growth Hormone Research Society Scientific Committee: Growth Hormone Deficiency in Adulthood and the Effects of Growth Hormone Replacement: A Review. J Clin Endocrinol Metab 83: 382-395.

2. Thorner MO, Vance ML, Laws Jr ER, Huworth E, Kovacs K, 1998 The anterior pituitary In: Wilson JD, Foster DW, Kronenberg HM, Reed Larsen P (eds) Williams Textbook of Endocrinology, Saunders Publications, pp, 249-341.

3. Rosen T, Bengtsson BA, 1990 Premature mortality due to cardiovascular disease in hypopituitarism. Lancet 336 : 285-288.

4. Gibney J, Wallace D, Spinks T, et al, 1999 The Effects of 10 Years of Recombinant Human Growth Hormone (GH) in Adult GH-Deficient Patients. J Clin Endocrinol Metab 84: 2596-2602.

5. Baum HB, Biller BMK, Finkelstein JS, et al, 1996 Effects of physiologic growth hormone therapy on bone density and body composition in patients with adult-onset growth hormone deficiency: a randomized, placebo-controlled trial. Ann Intern Med 125: 883-890.

6. Whitehead HM, Boreham C, McIlrath EM, et al, 1992 Growth hormone treatment of adults with growth hormone deficiency: results of a 13-month placebo controlled cross-over study. Clin Endocrinol 36: 45-52.

7. Bengtsson BA, Eden S, Lonn L, 1993 Treatment of adults with growth hormone deficiency with recombinant human growth hormone. J Clin Endocrinol Metab 76: 309-317.

8. Monson JP, 2002 Growth Hormone Deficiency in Adults In: Besser GM, Thorner MO (eds),Comprehensive Clin- 
ical Endocrinology, Mosby, pp, 47-56.

9. Rosen T, Bosaeus I, Tolli J, Lindstedt G, Bengtsson BA, 1993 Increased body fat mass and decreased extracellular fluid volume in adults with growth hormone deficiency. Clin Endocrinol 38: 63-71.

10. Rosen T, Wilhelmsen L, Landin-Wilhelmsen K, Lappas G, Bengtsson BA, 1997 Increased fracture rate in adult patients with hypopituitarism and GH deficiency. Eur J Endocrinol 137: $240-245$.

11. Kaufman JM, Taelman P, Vermeulen A, Vandeweghe M, 1992 Bone mineral status in growth hormone deficient males with isolated and multiple pituitary deficiencies of childhood onset. J Clin Endocrinol Metab 74: 118-123.

12. Wuster C, Abs R, Bengtsson BA, et al, 2001 The influence of growth hormone deficiency, growth hormone replacement therapy, and other aspects of hypopituitarism on fracture rate and bone mineral density. J Bone Min Res 16: 398-405.

13. Participants of the growth hormone research society workshop, 1998 Consensus Guidelines for the Diagnosis and Treatment of Adults with Growth Hormone Deficiency: Summary Statement of the Growth Hormone Research Society Workshop on Adult Growth Hormone Deficiency. J Clin Endocrinol Metab 83: 379-381.

14. Micic D, Casabiell X, Gualillo O, Pombo M, Dieguez C, Casanueva FF, 1999 Growth hormone secretagogues: the clinical future. Horm Res 51: Suppl 3: 29-33.

15. De Boer H, Block GJ, Vermann HJ, De Vries PM, van der Veen EA, 1992 Body composition in adult GH deficient men, assessed by anthro-pometry and bioimpendance analysis. J Clin Endocrinol Metab 75: 833-887.

16. Ezzat S, Fear S, Gaillard RC, et al, 2002 Gender-Specific responses of lean body composition and non-gender-specific cardiac function improvement after $\mathrm{GH}$ replacement in GH-deficient adults. J Clin Endocrinol Metab 87: 27252733.

17. Drake WM, Coyte D, Camacho-Hubner C, et al, 1998 Optimizing growth hormone replacement therapy by dose titration in hypopituitary adults. J Clin Endocrinol Metab 83: 3913-3919.

18. Stouthart PJ, de Ridder CM, Rekers-Mombarg LT, van der Waal HA, 1999 Changes in body composition during 12 months after discontinuation of growth hormone therapy in young adults with growth hormone deficiency from childhood. J Pediatr Endocrinol Metab 12: Suppl 1: 335338.

19. Christ ER, Carroll PV, Sonsken PH 2002 Adult growth hormone deficiency In: Wass JA, Shalet SM (eds), Oxford Textbook of Endocrinology and Diabetes, Oxford Publications, pp, 151-160.

20. Johansson AG, Burman P, Westermark K, Ljunghall S, 1992 The bone mineral density in acquired growth hormone deficiency correlates with circulating levels of insulin-like growth factor I. J Intern Med 232: 447-452.

21. Johannsson G, Rosen T, Bosaeus I, Sjostrom L, Bengtsson BA, 1996 Two years of growth hormone $(\mathrm{GH})$ treatment increases bone mineral content and density in hypopituitary patients with adult-onset GH deficiency J Clin
Endocrinol Metab 81: 2865-2873.

22. Biller BM, Sesmilo G, Baum HB, et al, 2000 Withdrawal of long-term physiological growth hormone $(\mathrm{GH})$ administration: differential effects on bone density and body composition in men with adult-onset GH deficiency. J Clin Endocrinol Metab 85: 970-976.

23. Christian Wuster 2000 Bone metabolism and bone mass in hypopituitary adults In: Bengtsson BA and Monson JP (eds) GH replacement in adults: the first 5 years of KIMS, pp, 94-104.

24. Drake WM, Rodriguez Arnao J, WeaverJU, et al, 2001 The influence of gender on the short and long-term effects of growth hormone replacement on bone metabolism and bone mineral density in hypopituitary adults: a 5-year study. Clin Endocrinol 54: 525-532.

25. Cuneo RC, Salomon F, Wiles CM, Sönksen PH, 1990 Skeletal muscle performance in adults with growth hormone deficiency. Horm Res 33: Suppl 4: 55-60.

26. Cuneo RC, Salomon F, Wiles CM, Hesp R, Sonksen $\mathrm{PH}, 1991$ Growth hormone treatment in growth hormone-deficient adults. I. Effects on muscle mass and strength. J Appl Physiol 70: 688-694.

27. Angelin B, Rudling M, 1994 Growth hormone and hepatic lipoprotein metabolism. Curr Opin Lipidol 5: 160165.

28. De Boer H, Blok GJ, Voerman HJ, Phillips M, Schouten JA, 1994 Serum lipid levels in growth hormone-deficient men. Metabolism 43: 199-203.

29. Cuneo RC, Salomon F, Watts GF, Hesp R, Sonksen PH, 1993 Growth hormone treatment improves serum lipids and lipoproteins in adults with growth hormone deficiency. Metabolism 42: 1519-1523.

30. Attanasio AF, Bates PC, Ho KKY, et al, 2002 Human growth hormone replacement in adult hypopituitary patients: Long-term effects on body composition and lipid status 3-year results from the HypoCCS Database. J Clin Endocrinol Metabol 87: 1600 -1606.

31. Eden S, Wiklund O, Oscarsson J, Rosen T, Bengtsson BA, 1993 Growth hormone treatment of growth hormonedeficient adults results in a marked increase in $\mathrm{Lp}(\mathrm{a})$ and HDL cholesterol concentrations. Arterioscler Thromb 13: 296-301.

32. Johannsson G, Oscarsson J, Rosen T, et al, 1995 Effects of 1 year of growth hormone therapy on serum lipoprotein levels in growth hormone-deficient adults. Arterioscler Thromb Vasc Biol 15: 2142-2150.

33. Hew F, Koschmann M, Christopher M, et al, 1996 Insulin resistance in growth hormone deficient adults: defects in glucose utilization and glucogen synthase activity. J Clin Endocrinol Metab 81: 555-564.

34. Svensson J, Fowelin J, Landin K, Bengtsson BA, Johansson JO, 2002 Effects of seven years of GH replacement on insulin sensitivity in GH deficient adults. J Clin Endocrinol Metab 87: 2121-2127.

35. Florakis D, Hung V, Kaltsas G, et al, 2000 Sustained reduction in circulating cholesterol in adult hypopituitary patients given low dose titrated growth hormone replacement therapy: a two year study. Clin Endocrinol 53: 453- 
459.

36. Isgaard J, Wahlander H, Adams MA, Friberg P, 1994 Increased expression of growth hormone receptor mRNA and insulin-like growth factor-I mRNA in volume-overloaded hearts. Hypertension 23: 884-888.

37. Isgaard J, Nilsson A, Vikman K, Isaksson OG, 1989 Growth hormone regulates the level of insulin-like growth factor-I mRNA in rat skeletal muscle. J Endocrinol 120: 107-112.

38. Evans LM, Davies JS, Goodfellow J, Rees JA, Scanlon MF, 1999 Endothelial dysfunction in hypopituitary adults with growth hormone defi-ciency. Clin Endocrinol 50: 457 . 464.

39. Rosen T, Eden S, Larson G, Wilhelmsen L, Bengtsson BA, 1993 Cardiovascular risk factors in adult patients with growth hormone deficiency. Acta Endocrinol 129: 195-200.

40. Johansson JO, Landin K, Tengborn L, Rosen T, Bengtsson BA, 1994 High fibrinogen and plasminogen activator inhibitor activity in growth hormone-deficient adults. Arterioscler Thromb 14: 434 -437.

41. Markussis V, Beshyah SA, Fisher C, Sharp P, Nicolaides AN, Johnston DG, 1992 Detection of premature atherosclerosis by high-resolution ultrasonography in symptomfree hypopituitary adults. Lancet 340: 1188 -1192.

42. Sverrisdottir YB, Elam M, Herlitz H, Bengtsson BA, Johannsson G, 1998 Intense sympathetic nerve activity in adults with hypopituitarism and untreated growth hormone deficiency. J Clin Endocrinol Metab 83: 1881-1885.

43. Boger RH, Skamira C, Bode-Boger SM, et al, 1996 Nitric oxide may mediate the hemodynamic effects of recombinant growth hormone in patients with acquired growth hormone deficiency. A double-blind, placebo-controlled study. J Clin Invest 98: 2706-2713.

44. Pfeifer M, Verhovec R, Zizek B, Prezelj J, Poredos P, Clayton RN, 1999 Growth hormone (GH) treatment reverses early atherosclerotic changes in DH-deficient adults. J Clin Endocrinol Metab 84: 453-457.

45. Pfeifer M, Verhovec R, Zizek B, 1999 Growth hormone $(\mathrm{GH})$ and atherosclerosis: changes in morphology and function of major arteries during $\mathrm{GH}$ treatment. Growth Horm IGF Res 9: Suppl A: 25-30.

46. Colao A, Cuocolo A, Di Somma C, et al, 2000 Does the age of onset of growth hormone deficiency affect cardiac performance? A radionuclide angiography study. Clin Endocrinol 52: 447-455.

47. Sacca L, Cittadini A, Fazio S, 1994 Growth hormone and the heart. Endocr Rev 15: 555-573.

48. Amato G, Carella C, Fazio S, et al, 1993 Body composition, bone metabolism, and heart structure and function in growth hormone $(\mathrm{GH})$-deficient adults before and after GH replacement therapy at low doses. J Clin Endocrinol Metab 77: 1671-1676.

49. Caidahl K, Eden S, Bengtsson BA, 1994 Cardiovascular and renal effects of growth hormone. Clin Endocrinol 40: 393-400.

50. Rosen T, Wiren L, Wilhelmsen L, Wiklund I, Bengtsson BA, 1994 Decreased psychological well being in adult patients with growth hormone deficiency. Clin Endocrinol
40: 111- 116

51. Drake WM, Howell SJ, Monson JP, Shalet SM, 2001 Optimizing GH therapy in adults and children. Endo Reviews 22: 425-450.

52. Mc Gauley G, 1989 Quality of life assessment before and after growth hormone treatment in adults with growth hormone deficiency. Acta Paediatr Scand 356: Suppl: 5559.

53. Elizabeth Hernberg-Stahl, Anton Luger, Roger Abs, et al, 2001 Healthcare Consumption Decreases in Parallel with Improvements in Quality of Life during GH Replacement in Hypopituitary Adults with GH Deficiency, J Clin Endocrinol Metab 86: 5277-5281.

54. Drake WM, Johannsson G 2000 Individual susceptibility to growth hormone In: Bengtsson BA, Monson JP (eds), $\mathrm{GH}$ replacement in adults: the first 5 years of KIMS, pp, 165-181.

55. American association of clinical endocrinologists, 2003 Growth Hormone Guidelines. Endocr Pract 9: 65-76.

56. Statement from the Growth Hormone Research Society, 2001 Critical Evaluation of the Safety of Recombinant Human Growth Hormone Administration. J Clin Endocrinol Metab 86: 1868-1870.

57. Salomon F, Cuneo RC, Hesp R, Sonksen PH, 1989 The effects of treatment with recombinant human growth hormone on body composition and metabolism in adults with growth hormone deficiency. N Engl J Med 321: 17971803.

58. Bengtsson B, Eden S, Lonn L, et al, 1993 Treatment of adults with growth hormone $(\mathrm{GH})$ deficiency with recombinant human GH. J Clin Endocrinol Metab 76: 309-317.

59. Jorgensen JO, Flyvbjerg A, Dinesen J, et al, 1987 Serum profiles and short-term metabolic effect of pituitary and authentic biosynthetic human growth hormone in man.Adouble-blind cross-over study. Acta Endocrinol 116: 381-386.

60. De Boer H, Blok GJ, Popp-Snijders C, Stuurman L, Baxter RC, van der Veen E, 1996 Monitoring of growth hormone replacement therapy in adults, based on measurement of serum markers. J Clin Endocrinol Metab 81: 13711977.

61. Wilton P, Koppeschaar HPF 2000 Safety of growth hormone replacement In: Bengtsson B A, Monson JP (eds), $\mathrm{GH}$ replacement in adults: the first 5 years of KIMS, pp, 182-189.

62. Holmes SJ, Shalet SM, 1995 Which adults develop sideeffects of growth hormone replacement? Clin Endocrinol 43: 143-149.

63. Frajese G, Drake WM, Loureiro R, et al, 2001 Hypothalamo-Pituitary Surveillance Imaging in Hypopituitary Patients Receiving Long-Term GH Replacement Therapy. J Clin Endocrinol Metab 86: 5172-5175.

64. Pollak M, Beamer W, Zhang JC, 1998-99 Insulin-like growth factors and prostate cancer. Cancer Metastasis Rev 17: 383-390.

65. Toniolo P, Bruning PF, Akhmedkhanov A, et al, 2000 Serum insulin-like growth factor-I and breast cancer. Int J Cancer 88: 828-832. 
66. Stavrou S, Kleinberg D, 2001 Diagnosis and management of growth horemone deficiency in adults. Endocr Metab Clinics North Amer 30: 545- 563.

67. Weaver JU, Thaventhiran L, Noonan K, et al, 1994 The effect of growth hormone replacement on cortisol metabolism and glucocorticoid sensitivity in hypopituitary adults. Clin Endocrinol 41: 639-648.

68. Gelding SV, Taylor NF, Wood PJ, et al, 1998 The effect of growth hormone replacement therapy on cortisol-cortisone interconversion in hypopituitary adults: evidence for growth hormone modulation of extrarenal 11 betahydroxysteroid dehydrogenase activity. Clin Endocrinol 48: 153-162.

69. Monson JP, Bengtsson BA 2000 Future directions of growth hormone research In: Bengtsson BA, Monson JP (eds), GH replacement in adults: the first 5 years of KIMS, pp, 202-208.

70. Vance ML, Mauras N, 1999 Drug Therapy: Growth Hormone Therapy in Adults and Children. N Engl J Med 341: 1206-1216.

71. Takala J, Ruokonen E, Webster NR, et al, 1999 Increased Mortality Associated with Growth Hormone Treatment in Critically Ill Adults. N Engl J Med 341: 785-792.

72. Holloway L, Kohlmeier L, Kent K Marcus R, 1997 Skeletal Effects of Cyclic Recombinant Human Growth Hormone and Salmon Calcitonin in Osteopenic Postmenopausal Women. J Clin Endocrinol Metab 82: 1111-1117.

73. Johannsson J, Marin P, Lonn L, et al, 1997 Growth Hormone Treatment of Abdominally Obese Men Reduces Abdominal Fat Mass, Improves Glucose and Lipoprotein Metabolism, and Reduces Diastolic Blood Pressure. J Clin Endocrinol Metab 82: 727-734.

74. Rutherford OM, Jones DA, Round JM, Buchanan CR, Preece MA, 1991 Changes in skeletal muscle and body composition after discontinuation of growth hormone treatment in growth hormone deficient young adults Clin Endocrinol. 34: 469-475.

75. Colle M, Auzerie J, 1993 Discontinuation of growth hormone therapy in growth hormone deficient patients: assessment of body fat mass using bioelectrical impedance.
Horm Res 39: 192-196.

76. Ranke MB, Monson JP 2000 Continuing the treatment of growth hormone deficiency during the transition from childhood to adulthood In: Bengtsson BA, Monson JP (eds), GH replacement in adults: the first 5 years of KIMS, pp, 190-201.

77. de Boer H, van der Veen EA, 1997 Why retest young adults with childhood-onset growth hormone deficiency? J Clin Endocrinol Metab 82: 2032-2036.

78. Bing-You RG, Denis MC, Rosen CJ, 1993 Low bone mineral density in adults with previous hypothalamic-pituitary tumors: correlations with serum growth hormone responses to GH-releasing hormone, insulin-like growth factor I, and IGF binding protein 3. Calcif Tissue Int 52: 183-187.

79. Holmes SJ, Economou G, Whitehouse RW, Adams JE, Shalet SM, 1994 Reduced bone mineral density in patients with adult onset growth hormone deficiency. J Clin Endocrinol Metab 78: 669-674.

80. Attanasio AF, Lamberts SW, Matranga AM, et al, 1997 Adult growth hormone (GH)-deficient patients demonstrate heterogeneity between childhood onset and adult onset before and during human $\mathrm{GH}$ treatment. Adult Growth Hormone Deficiency Study Group. J Clin Endocrinol Metab 82: 82-88.

81. Rutherford OM, Jones DA, Round JM, Preece MA, 1989 Changes in skeletal muscle after discontinuation of growth hormone treatment in young adults with hypopituitarism. Acta Paediatr Scand 356: Suppl 61-74.

82. Rosen T, Johannsson G, Hallgren P, Caidahl K, Bosaeus I, Bengtsson BA, 1994 Beneficial effects of 12 months replacement therapy with recombinant human growth hormone to growth hormone deficient adults. Endocrinol Metab 1: 55-66.

83. Weaver JU, Monson JP, Noonan K, John WG, Edwards A, Evans KA, 1995 The Effect of Low Dose Recombinant Human Growth Hormone Re-placement on Regional Fat Distribution, Insulin Sensitivity, and Cardio-vascular Risk Factors in Hypopituitary Adults. J Clin Endocrinol Metab 80: 153-159. 